Goldschmidt 2021 Abstract

https://doi.org/10.7185/gold2021.7588

\section{A reanalysis-based study of desert dust in Northern Africa, the Middle East and Europe in a recent decade}

ENZA DI TOMASO ${ }^{1}$, JERÓNIMO ESCRIBANO ${ }^{1}$, PAUL GINOUX $^{2}$, SARA BASART ${ }^{1}$, FRANCESCA MACCHIA $^{1}$, FRANCESCA BARNABA ${ }^{3}$, MIGUEL CASTRILLO ${ }^{1}$, PAOLA FORMENTI $^{4}$, ORIOL JORBA ${ }^{1}$, LUCIA MONA ${ }^{5}$, GILBERT MONTANÉ ${ }^{1}$, MICHAIL MYTILINAIOS ${ }^{5}$, VINCENZO OBISO $^{1,6}$, NICK SCHUTGENS ${ }^{7}$, ATHANASIOS VOTSIS ${ }^{8}$, ERNEST WERNER ${ }^{9}$ AND CARLOS PÉREZ GARCÍA$\mathrm{PANDO}^{10,11}$

${ }^{1}$ Barcelona Supercomputing Center (BSC)

${ }^{2}$ NOAA Geophysical Fluid Dynamics Laboratory (GFDL)

${ }^{3}$ Consiglio Nazionale delle Ricerche-Istituto di Scienze dell'Atmosfera e del Clima (CNR-ISAC)

${ }^{4}$ LISA, UMR CNRS 7583, Université Paris-Est-Créteil, Université de Paris, Institut Pierre Simon Laplace (IPSL)

${ }^{5}$ Consiglio Nazionale delle Ricerche-Istituto di Metodologie per 1'Analisi Ambientale (CNR-IMAA)

${ }^{6}$ NASA Goddard Institute for Space Studies

${ }^{7}$ Faculty of Science, Vrije Universiteit

${ }^{8}$ Finnish Meteorological Institute (FMI)

${ }^{9}$ State Meteorological Agency (AEMET)

${ }^{10}$ ICREA and Barcelona Supercomputing Center (BSC)

${ }^{11}$ ICREA, Catalan Institution for Research and Advanced

Studies

Presenting Author: enza.ditomaso@bsc.es

Desert dust aerosols are highly variable in space and time, and, therefore, require a continuous monitoring by measurements done either in-situ or remotely by satellite, air-borne and groundbased sensors. Due to the sparse nature of observations, a four dimensional reconstruction of past dust conditions is best done by combining observations with short-range forecast reruns while using a consistent modelling scheme over time. Such observation- and model-based reconstructions are known as reanalysis datasets.

We will discuss the spatial and temporal distribution of desert dust in a recent decade based on a high-resolution regional reanalysis which has been recently produced by the Barcelona Supercomputing Center (BSC). The reanalysis covers the domain of Northern Africa, the Middle East and Europe at a horizontal resolution of $0.1^{\circ}$ and a time resolution of 3 hours. This dataset has been obtained by combining satellite remote sensing observations of dust based on MODIS Deep Blue retrievals of Aerosol Optical Depth [1] with a dynamical model, more specifically, the dust module of the MONARCH chemical weather system $[2,3]$.

In particular, we will show here that the dust annual cycle is well reproduced through the different years of the study period (2007-2016). To support further our findings, we will discuss a thorough validation of the reanalysis dataset with AERONET observations.

The good quality of the BSC desert dust reanalysis makes it a useful tool in support of climate research and services, as well as for the development and refinement of environmental monitoring and mitigation strategies.

[1] Pu, B., and Ginoux, P.: The impact of the Pacific Decadal Oscillation on springtime dust activity in Syria. Atmospheric Chemistry and Physics, 16(21), 13431-13448, 2016

[2] Di Tomaso, E., Schutgens, N. A. J., Jorba, O., and Pérez García-Pando, C.: Assimilation of MODIS Dark Target and Deep Blue observations in the dust aerosol component of NMMB-MONARCH version 1.0, Geosci. Model Dev., 10, 11071129, doi:10.5194/gmd-10-1107-2017, 2017

[3] Klose, M., et al.: Mineral dust cycle in the Multiscale Online NonhydrostaticAtmospheRe CHemistry model (MONARCH) Version 2.0, Geoscientific Model Development, submitted, 2021. 